\title{
Plasma Membrane Effects of Sphingolipid- Synthesis Inhibition by Myriocin in CHO Cells: A Biophysical and Lipidomic Study
}

Bingen G. Monasterio

Universidad del País Vasco

Noemi Jiménez-Rojo

NCCR Chemical Biology, University of Geneva

Aritz B. García-Arribas

Universidad del País Vasco

Howard Riezman

NCCR Chemical Biology, University of Geneva

Félix M. Goñi

Universidad del País Vasco

Alicia Alonso ( $\nabla$ alicia.alonso@ehu.eus )

Universidad del País Vasco

\section{Research Article}

Keywords: sphingolipid, myriocin, serine palmitoyltransferase, CHO cells, LY-B cells, laurdan, atomic force microscopy, membrane fluidity, force spectroscopy, breakthrough force, membrane mechanical resistance

Posted Date: April 16th, 2021

DOl: https://doi.org/10.21203/rs.3.rs-419785/v1

License: (c) (1) This work is licensed under a Creative Commons Attribution 4.0 International License. Read Full License 


\section{Abstract}

Two main strategies for establishing the cellular effects of a given enzyme activity suppression are (a) the use of a stably mutated cell line that lacks a functional gene, or (b) treating the wild type with an inhibitory compound that affects the same gene-product protein. In this work, myriocin was used to block the serine palmitoyltransferase (SPT) enzyme of $\mathrm{CHO}$ cells and the subsequent biophysical changes in membranes were measured and compared with results obtained with a genetically modified $\mathrm{CHO}$ cell line containing a defective SPT (the LY-B cell line). Similar effects were observed with both approaches: sphingomyelin values were markedly decreased in myriocin-treated $\mathrm{CHO}$ cells and, in consequence, their membrane molecular order (measured as laurdan general polarization) and mechanical resistance (AFMmeasured breakthrough force values) happened to be lower than in the native, non-treated cells. Cells treated with myriocin reacted homeostatically to maintain membrane order, synthesizing more fully saturated and less polyunsaturated glycerophospholipids than the non-treated ones, although they achieved it only partially, their plasma membranes remaining more fluid and less penetrable than those from the control cells.

\section{Introduction}

Sphingolipids (SL) are considered as fundamental structural components of biological membranes. In addition, in the last years they have been found to be a source of bioactive molecules. In the latter capacity, SL are involved in many important and different biological roles, such as cell proliferation, differentiation, apoptosis, and ageing, as well as embryogenesis ${ }^{1}$. Most SL metabolic reactions are bidirectional, thus metabolites are interconvertible and it is often the specific species ratio that determines the cell fate ${ }^{2}$. Besides, SL metabolite effects vary depending on the cell type, subcellular compartment, cell cycle phase, or extracellular stimulus ${ }^{3,4}$. An example of the complex effects of SL metabolites is given by sphingosine-1-phosphate and ceramide (Cer), the former is a second messenger for cell survival and proliferation, while the latter can induce cell death ${ }^{5,6}$.

Many aspects of SL roles in cells remain to be understood. One testable approach consists of examining the effects of SL restriction in cells. Lowering SL concentrations in the growth medium has little effect by itself, since mammalian cells can synthesize their own SL. Thus, researchers in this field have focused their attention on the first, pacemaker enzyme in the SL synthetic pathway, serine palmitoyltransferase (SPT). This enzyme catalyzes the reaction between palmitoyl-CoA and L-serine to synthesize 3-dehydroD-sphinganine ${ }^{7}$. From that point onwards, all SL can be synthesized in a relatively small number of steps. Combining SL restriction in the growth medium (usually lowering the concentration of fetal bovine serum, FBS) with annulling SPT activity could lead to a very severe dearth of SL in the cells. SPT activity can be removed following one of at least two strategies, either genetic mutation or chemical inhibition.

As an example of the former approach, using a genetic selection method in $\mathrm{CHO}^{8}$, the Hanada lab isolated the defective LY-B cell line, which had a loss of SPT enzyme function through a defective SPTLC1 subunit. The mutant cells maintained the ability to take up and metabolize exogenous sphingoid 
bases from the culture medium ${ }^{8}$. LY-B cells have been used in multiple studies exploring SL effects, and $S L$ interaction with glycerophospholipid metabolism ${ }^{9-12}$. Mutant LY-B and wild type $\mathrm{CHO}$ cells could be comparatively studied to determine the effect of SL depletion on the cell membrane biophysical properties. This was the approach in our previous study ${ }^{13}$ in which we found that the lowest FBS concentration that allowed LY-B cell growth, though at a slow rate, under our conditions was $0.04 \%$, i.e. 250 -fold less than the standard (10\%) concentration. Cells grown under those limiting SL concentrations remained viable for at least $72 \mathrm{~h}$. A significant decrease in the rigidity of LY-B cell membranes was observed using laurdan fluorescence, as well as a decrease in membrane breakthrough forces (membrane nanomechanical resistance) assessed by atomic force microscopy (AFM) ${ }^{13}$. Concomitantly, the SL concentration in membranes was drastically reduced, with partially compensating changes in glycerophospholipids ${ }^{13}$.

An alternative strategy to detect the effects of an overall SL decrease is the specific inhibition of the SPT enzyme. Among the non-natural selective inhibitors of this enzyme are $\beta$-chloroalanine ${ }^{14}$ and Lcycloserine ${ }^{15}$. In addition, SPT can be inhibited with natural products such as stereoisomers of the antifungal sphingofungin $\mathrm{B}^{16}$ and the antifungal antibiotic myriocin ${ }^{17-19}$, isolated from Myriococcum albomyces ${ }^{20}$. Myriocin has been employed in a variety of studies. In Jurkat acute leukemia cells, myriocin blocks the de novo synthesis of ceramide ${ }^{21}$. In particular, it inhibits the synthesis of long-chain Cer species which stimulate proteasomal activation with subsequent activation of caspases ${ }^{22}$. Myriocin has also been used for identifying several SPT inhibition effects in membrane structure and functions. For example, the role of skin sphingosine in the permeation of levodopa (a hydrophilic drug) across rat skin ${ }^{23}$, the paradoxical effects on barrier permeability homeostasis ${ }^{24}$ and the delays of mammalian epidermal barrier recovery after acute perturbation ${ }^{25}$ have been studied. In a recent contribution from one of our laboratories, the cellular responses to SL depletion have been described, highlighting the importance of $S L$ in particular pathways such as protein secretion from the endoplasmic reticulum ${ }^{26}$.

In the present study, we explore the effects of myriocin-induced SPT inactivation in CHO cells. In particular, the consequences on cell growth, lipid composition, and membrane physical properties have been considered. A novel plasma membrane (PM) preparation ('PM patches') has been used ${ }^{27,28}$. The study has been performed following the steps of the previous publication with genetically modified $\mathrm{CHO}$ cells (LY-B cells $)^{13}$, so that the respective results can be compared. The LY-B study design is such that the effects of FBS removal, namely loss of sphingolipids and loss of other components in the serum, cannot be properly differentiated. Myriocin allows the specific inhibition of SPT even in the presence of a full complement of FBS. Conversely, our study might unveil myriocin effects other than SPT inhibition.

\section{Results}

Growth and viability. Cell count measurements were performed using a BioRad TC20 hemocytometer to assess myriocin treatment effects on $\mathrm{CHO}$ (wild type) and LY-B (SPT-defective) cell division ratio and 
integrity. Figure 1A shows a comparison between myriocin-treated and non-treated cell growth ratio in SLdeficient (containing $0.04 \%$ FBS) medium. Student's t-test revealed a statistically significant difference between myriocin-treated and non-treated $\mathrm{CHO}$ cell division ratio; myriocin treatment made $\mathrm{CHO}$ cell growth much slower (Fig. 1A). The LY-B cell division ratio was equally low in the presence or absence of myriocin. In addition, there was no statistically significant difference between treated $\mathrm{CHO}$ cells and nontreated/treated LY-B cells grown in SL-deficient medium. Comparison between cell division ratios in standard and deficient medium is shown in figures S1A and S1B; myriocin treatment had no effect on the cell division ratio when $\mathrm{CHO}$ or $\mathrm{LY}-\mathrm{B}$ cells were grown in standard medium, but some inhibition took place in $\mathrm{CHO}$ cells grown on deficient medium (Fig. S1A and S1B).

To ascertain that the poor cell growth at low FBS concentrations was indeed due to the lack of SL, and not to the absence of other nutrients putatively present in FBS, it was tested whether myriocin-treated $\mathrm{CHO}$ cells were able to reach the full growth rates when the SL-deficient medium was supplemented with SL. For this purpose, equimolar mixtures of egg PC and SM or Sph were sonicated in DMEM:F12 medium and added to the culture flasks in various amounts. A good recovery was achieved with Sph (Fig. 1B and S1E) or SM (Fig. S1C) supplementation.

Figure 1B shows that myriocin-treated $\mathrm{CHO}$ cells grown on $\mathrm{SL}$-deficient medium for $72 \mathrm{~h}$ reached $\approx 78 \%$ of the control growth when $0.0125 \mathrm{mg}$ Sph was added per T25 culture flask ( $8 \mu \mathrm{M}$ final concentration), while larger concentrations appeared to have a toxic effect. In the case of SM, $0.1 \mathrm{mg} /$ flask or higher (40 $\mu \mathrm{M}$ or higher) supplementation made myriocin-treated $\mathrm{CHO}$ cells reach $75 \%$ of the control growth (Fig. S1C), as seen in Monasterio et al. ${ }^{13}$. It was concluded that myriocin-mediated lack of SPT activity could be masked when appropriate SL supplementation was added in the deficient-medium. The toxic effect of Sph might be due to its membrane-permeabilizing effects ${ }^{29}$, a phenomenon not observed with SM.

Next, cell viability was tested performing flow-cytometry analysis of cells stained with Annexin-V-FITC and propidium iodide (Fig. 1C). Flow-cytometry analyses demonstrated that $84 \%$ of $\mathrm{CHO}$ cells grown in SL-deficient medium for $72 \mathrm{~h}$ and treated with $2.5 \mu \mathrm{M}$ myriocin remained viable (Fig. 1C), similar to the $86 \%$ value obtained with non-treated LY-B cells grown in SL-deficient medium ${ }^{13}$.

Lysenin-staining. Lysenin is a peptide toxin that binds specifically SM in membranes. A non-toxic fragment of lysenin was expressed as a fusion peptide with mCherry, NT-lysenin-mCherry, as detailed under Methods. Cells were stained with SM-specific NT-lysenin-mCherry, and visualized with confocal microscopy (Fig. 2). Non-myriocin treated CHO cells grown in standard (Fig. 2A) or SL-deficient medium (Fig. 2C), as well as treated $\mathrm{CHO}$ cells grown in standard medium (Fig. 2B), appeared thoroughly stained with mCherry. However, only little dots of mCherry were seen in myriocin-treated $\mathrm{CHO}$ cells grown in SLdeficient medium (Fig. 2D), indicating a remarkable SM decrease in this sample. In LY-B cells (Fig. 2E-H), the lysenin signal decrease observed in Fig. $2 \mathrm{G}$ and $2 \mathrm{H}$ is a direct reflection of their mutated SPT enzyme ${ }^{13}$ and not due to the myriocin treatment, as differences are not seen between non-treated (Fig. 2G) and treated (Fig. 2H) LY-B cells grown in deficient medium. 
For lysenin-mCherry quantification, flow-cytometry was performed (Fig. S2). In the first $24 \mathrm{~h}, \mathrm{CHO}$ cells grown in a deficient medium and treated with $2.5 \mu \mathrm{M}$ myriocin, underwent a two-fold lysenin signal decrease compared with $\mathrm{CHO}$ cells grown in a standard medium (Fig. S2A). On the contrary, there was no statistically significant difference between $\mathrm{CHO}$ cells grown in standard medium and non-treated $\mathrm{CHO}$ cells grown in deficient medium (Fig. S2A) as seen in Monasterio et al. ${ }^{13} .72 \mathrm{~h}$ were needed to achieve a total SM depletion in myriocin-treated $\mathrm{CHO}$ cells grown in deficient medium (Fig. S2B). In the case of LY-B cells, myriocin treatment did not affect the mCherry-lysenin values (Fig. S2C and S2D), as there was no statistically significant difference between treated and non-treated LY-B cells grown in a deficient medium, neither after $24 \mathrm{~h}$ (Fig. S2C), nor after $72 \mathrm{~h}$ (Fig. S2D).

For an easier comparison between genetically mutated LY-B and myriocin-treated $\mathrm{CHO}$ cells, figure S2E shows a comparative table of CHO/LYB signal ratios. The most significant conclusion is that after $24 \mathrm{~h}$ myriocin treatment, $\mathrm{CHO}$ cells had twice the signal intensity of $\mathrm{LY}-\mathrm{B}$, and that the difference was suppressed after $72 \mathrm{~h}$. No statistically significant difference was found between LY-B and myriocintreated $\mathrm{CHO}$ cells at this stage. Results indicate, as expected, a faster SM depletion in mutated, SPTdefective $\mathrm{LY}-\mathrm{B}$, than in myriocin-treated $\mathrm{CHO}$ cells, the latter containing a full amount of $\mathrm{SL}$ at the start of the experiment.

In parallel, $\mathrm{PM}$ patches of myriocin-treated and non-treated $\mathrm{CHO}$ cells were also visualized using lyseninmCherry. PM patches of $\mathrm{CHO}$ cells treated with $2.5 \mu \mathrm{M}$ myriocin and grown in deficient medium for $72 \mathrm{~h}$ (Fig. S3A) exhibited little lysenin-mCherry signal dots (indicated with white arrows), while the non-treated $\mathrm{CHO}$ cell PM patches grown in the same medium were extensively stained (Fig. S3B).

In summary, both non-treated $\mathrm{CHO}$ and LY-B cell lines grew to a similar extent in standard medium (Fig. 1A). Myriocin was effective in reducing cell growth rates only for $\mathrm{CHO}$ cells grown under limiting SL conditions. When using SL-deficient medium, myriocin-treated $\mathrm{CHO}$ cells growth was similar to that of LY$\mathrm{B}$ and lower than that of non-treated $\mathrm{CHO}$ cells (Fig. 1A). Control growth of myriocin-treated cells in SLdeficient medium was recovered when the culture broth was supplemented with a proper SL (Fig. 1B). Lysenin fluorescence was largely decreased in myriocin-treated (but not in non-treated) $\mathrm{CHO}$ cells in the first $24 \mathrm{~h}$ of growth in deficient medium. Nevertheless, they contained higher SM amounts compared to non-treated LY-B cells (grown in deficient medium) and $72 \mathrm{~h}$ were needed to achieve a full lyseninmCherry signal depletion equivalent to the one observed in LY-B cells (Fig. 2, S2, S3).

\section{Membrane lipid order decreases with sphingolipid restriction}

Laurdan generalized polarization (GP) provides an estimation of membrane lipid molecular order ${ }^{30}$. To evaluate how SPT activity suppression affected the rigidity/fluidity of cell membranes, laurdan GP experiments were performed. GP values of myriocin-treated and non-treated $\mathrm{CHO}$ cells PM patches were measured using two-photon microscopy. 
Figure $3 \mathrm{~A}$ depicts a $\mathrm{PM}$ patch from a $\mathrm{CHO}$ cell grown in deficient medium and stained with laurdan. In the -1 to +1 color scale at the right hand of the picture, the red color and a value close to +1 indicated a more rigid/ordered region, while blue color and a value close to -1 indicated a more fluid region. The GP value of PM patches derived from $\mathrm{CHO}$ cells treated with $2.5 \mu \mathrm{M}$ myriocin and grown in deficient medium for $72 \mathrm{~h}$ (Fig. 3B) decreased on average from 0.41 to 0.37 compared with the non-treated $\mathrm{CHO}$ cells (Fig. 3A) grown in the same medium. The Student's t test showed that a statistically significant difference existed between myriocin-treated and non-treated CHO-cell PM patches.

In figure S4 whole cells stained with laurdan and the corresponding optically selected PM pixels are shown. In whole cell images (Fig. S4A, S4C, S4E and S4G) two different regions could be distinguished, the more ordered PM and the more disordered/fluid intracellular membranes. In a previous work we showed that the two GP values were around 0.5 for PM and 0.2 for intracellular membranes ${ }^{28}$, indicating that the PM was less fluid than the intracellular membranes, perhaps due to the high Chol concentration in this membrane, in turn putatively related to its barrier role ${ }^{31}$.

PM pixels of treated and non-treated $\mathrm{CHO}$ and $\mathrm{LY}$-B cells grown in SL-deficient medium for $72 \mathrm{~h}$ were measured for GP (Fig. S4B, S4D, S4F and S4H). The GP value of the PM region of myriocin-treated CHO cells decreased from 0.48 (Fig. S4B) down to 0.45 (Fig. S4F), while treated (Fig. S4H) and non-treated (Fig. S4D) LY-B cell PM GP value was constant at around 0.45. Student's $t$ test revealed that the difference between myriocin-treated $\mathrm{CHO}$ cells grown in SL-deficient medium was significantly lower. On the contrary, there was no statistically significant difference between treated and non-treated LY-B cell PM.

\section{Breakthrough force of myriocin-treated $\mathrm{CHO}$ cells plasma membranes is decreased}

Figure 4 shows the topology and breakthrough force distribution of PM patches derived from non-treated (Fig. 4A) and myriocin-treated (Fig. 4B) CHO cells grown in deficient medium for $72 \mathrm{~h}$. According to topographic images, even if membrane components other than the bilayer, perhaps (glyco)proteins or protein aggregates, gave rise to protruding elements, a minimum thickness of 4-5 nm that corresponds to the thickness of a lipid bilayer was measured ${ }^{32}$; no statistically significant difference in thickness was observed between treated and non-treated $\mathrm{CHO}$ cells.

The breakthrough force distributions showed a significant difference between the PM patches derived from non-treated ( $3.76 \mathrm{nN}$; Fig. 4A) and treated ( $2.77 \mathrm{nN}$; Fig. 4B) CHO cells grown in deficient medium. This result is similar to the one obtained in Monasterio et al. ${ }^{13}$ when LY-B cell PM patches exhibited a large decrease, from $4.64 \mathrm{nN}$ to $2.98 \mathrm{nN}$, when grown in normal or deficient medium ${ }^{13}$.

Breakthrough force measurements were in good agreement with laurdan GP values (Fig. 3). PM patches exhibited the expected behavior, the myriocin-treated $\mathrm{CHO}$ cells grown in deficient medium showing lower values in both parameters (Fig. 3 and Fig. 4), compared with non-treated cells. 


\section{Lipidomic analysis of myriocin-treated vs. non-treated $\mathrm{CHO}$ cells}

To understand the existing membrane order/disorder differences between myriocin-treated and nontreated $\mathrm{CHO}$ cells and their homeostatic regulation capacity, a lipidomic study of PM patches (Fig. 5) and whole cells (Fig. S5) was performed. A comprehensive description of the various lipid compositions can be seen in the supplementary material table S1. The data are given in mole\% of the lipid extract.

Plasma membrane patches. Some specific lipidomic results can be highlighted. Among the various SL classes, SM (by far the most abundant SL), Cer (an important SL in cell signaling), and HexCer (precursor of the complex glycosphingolipids) were selected (Fig. 5A-C). All three (SM, Fig. 5A; Cer, Fig. 5B and HexCer, Fig. $5 \mathrm{C}$ ) significantly decreased in $\mathrm{CHO}$ cell PM patches (0.04\% FBS) when treated with $2.5 \mu \mathrm{M}$ myriocin (73\% decrease for SM, 37\% for Cer, and $85 \%$ for HexCer). However, the corresponding SL values of LY-B patches remained unchanged, or even increased slightly (Fig. 5A-C), perhaps because of their low values in non-treated cells: even if SM (Fig. 5A), Cer (Fig. 5B), and HexCer (Fig. 5C) amounts were largely decreased in myriocin-treated $\mathrm{CHO}$ cell PM patches, they were still twice (or larger) those of the nontreated LY-B cells $(0.04 \%$ FBS). The latter observation is in agreement with the lysenin staining images in Fig. 2, S2, S3.

Glycerophospholipid (GPL) acyl chain saturation and length also play an important role in the membrane bilayer physical properties, specifically on its disorder/fluidity, unsaturated and shorter acyl-chain GPL increasing membrane fluidity ${ }^{33}$. In Fig. 5D and 5E the distribution of GPL saturation degree is shown. While in myriocin-treated LY-B cells GPL saturation degree in PM patches remained unchanged, in myriocin-treated $\mathrm{CHO}$ cells the fraction of fully saturated GPL increased (Fig. 5D) and that of polyunsaturated GPL (2-6 double bonds) decreased (Fig. 5E). In addition, PM patches from non-treated LY-B cells grown in deficient medium had a similar GPL saturation distribution as those from treated $\mathrm{CHO}$ cells grown in the same medium (Fig. 5D, E).

Considering GPL chain-length distribution, when myriocin-treated $\mathrm{CHO}$ cells were grown in deficient medium, their short 30-32 C acyl-chain GPL remained unchanged (Fig. 5F). Simultaneously, a slight but statistically significant increase in very long (42-44C) acyl-chain GPL was observed (Fig. 5H).

Whole cell extracts. The lipidomic distribution of treated and non-treated whole $\mathrm{CHO}$ and LY-B cells grown in deficient media is shown in figure S5. The results are remarkably similar to those found with the corresponding plasma membrane preparations, perhaps suggesting an active intracellular traffic.

Cholesterol. Cholesterol was determined by mass spectroscopy separately from the fatty acid-containing lipids, as indicated under Methods. The results are given in Table 2. Decreasing FBS concentration in the growth medium from $10-0.04 \%$ decreased cholesterol concentrations in the cell membranes by about one-half. However, myriocin failed to significantly affect the amount of cholesterol in cells grown under limiting SL concentrations. 
In summary, myriocin effects on lipid composition were almost exclusively detected under conditions when myriocin hampered cell growth, i.e. CHO cells grown under limiting SL conditions. SM (Fig. 5A), Cer (Fig. 5B), and HexCer (Fig. 5C) concentrations in the PM were markedly lower in myriocin-treated than in non-treated $\mathrm{CHO}$ cells. Even if treated cells exhibited a large SL decrease, their levels were still larger than those of non-treated LY-B cell PM patches. According to GPL acyl chain length and saturation, myriocintreated $\mathrm{CHO}$ cells synthesized longer (Fig. 5H) and more saturated (Fig. 5D) GPL, perhaps a homeostatic response to myriocin-mediated SM depletion. The correlation between $\mathrm{CHO}$ cell PM changes in lipid composition and in biophysical properties is graphically expressed in Fig. 6.

\section{Discussion}

Myriocin effects on cell growth and composition. Most natural compounds with potent SPT-inhibitory properties, such as myriocin, are structural analogues of $\mathrm{Sph}^{34}$, a bioactive molecule modulating a variety of cell functions ${ }^{35,36}$. The polyfunctionality of Sph might suggest that myriocin would have additional biological activities apart from the inhibitory effect of the de novo synthesis of SL. When an inhibitory compound is highly specific, the cellular effect that this compound produces should be the same as the one caused by the genetic inactivation of the target, the SPT enzyme in our case. On the contrary, if the cellular response to a drug is different from the one achieved by genetic inactivation of the target enzyme, the drug might have additional effects. In a previous investigation, we used a genetically modified $\mathrm{CHO}$ cell line defective in SPT (the LY-B cell line) to perform biophysical measurements and check their homeostatic response to SL deprivation ${ }^{13}$. In the current study, we have used myriocin to specifically inhibit SPT and compare the chemical inhibition results with the ones obtained after genetic modification (LY-B results) ${ }^{13}$, thus addressing myriocin specificity against the SPT enzyme activity.

When cell growth of myriocin-treated $\mathrm{CHO}$ and non-treated LY-B cells were compared, slight, no significant differences were found. Myriocin-treated $\mathrm{CHO}$ cells were able to recover to a large extent the control (nontreated $\mathrm{CHO}$ cell) growth rates when the SL-deficient medium was supplemented with Sph (Fig. 1B and Fig. S1F). When externally supplied to the culture medium, Sph is utilized for synthesis of Cer and complex SL in CHO cells, thereby bypassing the SPT reaction inhibition. A similar behavior was observed with SM supplementation (Fig. S1C). Nevertheless, control (non-treated CHO grown in deficient medium) values were not reached (Fig. 1B). This failure to recover full growth adding exogenous SL molecules in the presence of the SPT inhibitors could occur because some sphingosine-like compounds, as is the case for myriocin, are known to inhibit sphingosine kinase ${ }^{37}$. This inhibition would lead to the decrease of sphingosine-1-phosphate cell levels. Sphingosine-1-phosphate has been described as a second messenger favoring cell proliferation and survival ${ }^{38-40}$. According to other studies, growth rate recovery is not achieved either when the used SPT inhibitor is L-Cycloserine or $\beta$-chloro-L-alanine ${ }^{41}$ instead of myriocin.

Alternatively, the different growth rates of myriocin-treated and non-treated $\mathrm{CHO}$ cells (Fig. 1A) may be related to the over-production of HexCer observed in non-treated $\mathrm{CHO}$, but not in myriocin-treated $\mathrm{CHO}$ cell 
patches upon lowering FBS concentration in the medium (Fig. 5C). HexCer is at the origin of the complex glycosphingolipid biosynthetic pathway ${ }^{42}$. Glycosphingolipids are required for cellular differentiation and there are human diseases resulting from defects in their synthesis ${ }^{43}$.

Comparing the SL levels in PM patches derived from myriocin-treated and non-treated $\mathrm{CHO}$ cells grown in deficient medium, it can be concluded that the former exhibit significantly lower SL values. Three representative SL, SM (Fig. 5A), Cer (Fig. 5B), and HexCer (Fig. 5C), were largely decreased, by 73\%, 37\%, and $85 \%$ respectively. These results are in good agreement with the ones published by Ziulkoski et al. ${ }^{44}$, who achieved a 40\%-61\% SM decrease using fumonisin B1 and $\beta$-chloroalanine. An important myriocin effect was that a more rapid SM depletion was obtained in mutated defective- SPT containing LY-B than in the myriocin-treated $\mathrm{CHO}$ cells (Fig. 2, S2, S3). In addition, SM, Cer and HexCer levels, even if their amounts were markedly decreased by myriocin treatment, were still larger in treated $\mathrm{CHO}$ cells than in non-treated LY-B cells $(0.04 \%$ FBS).

Lipid composition and physical properties. SL depletion is probably what makes PM patches derived from myriocin-treated $\mathrm{CHO}$ cells to show a decreased laurdan GP (indicating a decreased lipid order, or increased bilayer fluidity) (Fig. 3 and S4) and a lowered breakthrough force distribution (increased membrane penetrability) (Fig. 4). GP images from PM patches derived from myriocin-treated $\mathrm{CHO}$ cells appeared to be homogenous, but the presence of nanodomains could not be ruled out because of the spatial and temporal resolution limit of conventional two-photon microscopy ${ }^{45-47}$.

In addition, a comparison of myriocin-treated and non-treated $\mathrm{CHO}$ cells showed changes in their GPL distribution. Myriocin-treated cells contained more fully saturated (Fig. 5D) and less polyunsaturated (Fig. 5E) GPL than non-treated ones. This could partially help to maintain membrane rigidity under conditions of low SM. This observation is in accordance with results obtained from the LY-B cells containing a mutated, non-functional SPT ${ }^{13}$. According to chain length distribution, $\mathrm{LY}$-B cells grown in deficient medium contain more short-chain fatty acids (C30-32C per GPL molecule) than myriocin-treated $\mathrm{CHO}$ cells ${ }^{13}$. A summary of the chemical and physical changes induced by myriocin is shown in Fig. 6 .

Chemical vs. genetic suppression of SPT activity. The present study presents a phenotypic comparison between mutant cells (LY-B) specifically defective in a cellular function (de novo SL synthesis), and wildtype $\mathrm{CHO}$ cells exposed to a chemical inhibitor of the SPT activity function (myriocin) as a rational approach for evaluating how specific an inhibitor compound can be. The main difference between the two approaches is that LY-B cells lack a functional SPT complex because they cannot synthesize the LCB1 subunit, while the myriocin-mediated inhibition only blocks the SPT function, but the protein is still present. This may have important implications, for example the drug-inhibited protein may lack a certain activity but may still interact with some binding partners, as many proteins have multiple activities and/or functions and may participate in multiple disparate pathways, processes, and/or multiprotein complexes and structures ${ }^{48-50}$. 
Considering the above data, very similar results were achieved with both the pharmacological and genetic tools. Myriocin-treated SM-depleted $\mathrm{CHO}$ cells reacted to maintain membrane order undergoing a homeostatic response, although they achieved it only partially, as their PM were more fragile when grown in SL-deficient medium. The same occurred with non-treated LYB cells ${ }^{13}$.

The capacity shown by certain cells, e.g. myriocin-treated $\mathrm{CHO}$ cells or genetically modified LY-B cells, to grow under extremely demanding low concentrations of SL opens the way to a variety of functional studies on the role of SL in membranes. Nevertheless, natural compounds as myriocin or fumonisin may display toxicity in humans ${ }^{58}$, hence the need for chemical inhibitors more suitable for human studies. A therapy acting on SPT activity might show good results in the treatment of cardiovascular diseases, such as atherosclerosis ${ }^{51,52}$. Other studies provided evidence that inhibition of de novo Cer synthesis improves glucose homeostasis and enhances whole-body insulin responsiveness in rodent models of type-2 diabetes ${ }^{53}$. Moreover, it has been shown that it reduces body weight, ameliorates glucose homeostasis, and reverses hepatic steatosis in diet-induced nonalcoholic fatty liver disease ${ }^{54}$. In addition, it has been seen that the blockage of de novo synthesis of Cer and HexCer significantly suppresses neurodegenerative phenotypes associated with a-synuclein overexpression ${ }^{55}$.

\section{Methods}

\section{Materials}

Wild type $\mathrm{CHO}$ (ATCC, Manassas, VA, US) and a serine-SPT deficient CHO cell line, known as LY-B ${ }^{8}$ (RIKEN BioResource Research Center, Koyadai, Japan), were used. Cell culture products: DMEM:F12 (Dulbecco's Modified Eagle Medium: Nutrient Mixture F-12), penicillin, streptomycin, and GlutaMax supplement were purchased from Thermofisher (Waltham, MA, US). Fetal bovine serum (FBS) was lot no. 2176377 from Gibco (Dublin, Ireland). Organic solvents were from Thermofisher (Waltham, MA, US). All fluorophores were purchased from Thermofisher (Waltham, MA, US). Salts for buffer preparation $\left(\mathrm{KCl}, \mathrm{NaCl}, \mathrm{CaCl}_{2}\right.$, HEPES), myriocin and lipids were purchased from Sigma Aldrich (Sigma Aldrich, San Luis, MO, US). All reagents (salts and organic solvents) were of analytical grade.

\section{Cell growth}

Wild type $\mathrm{CHO}$ (ATCC, Manassas, Virginia, U.S.) and a serine-SPT deficient $\mathrm{CHO}$ cell line, known as LY-B ${ }^{8}$ (RIKEN BioResource Research Center, Koyadai, Japan), were used in this study. Cells were grown on DMEM:F12 (Dulbecco's Modified Eagle Medium: Nutrient Mixture F-12) medium containing 10\% FBS (Fetal Bovine Serum), $100 \mathrm{U} / \mathrm{ml}$ penicillin, $100 \mathrm{U} / \mathrm{ml}$ streptomycin, and $6 \mathrm{mM}$ glutamine (GlutaMax supplemented) at $37^{\circ} \mathrm{C}$ and $5 \% \mathrm{CO}_{2}$ humidified atmosphere. All cell culture products were purchased from Thermofisher (Waltham, MA, US).

Myriocin treatment. CHO and LY-B cells were first seeded in DMEM:F12 medium containing 10\% FBS, 100 $\mathrm{U} / \mathrm{ml}$ penicillin and $100 \mathrm{U} / \mathrm{ml}$ streptomycin, and $6 \mathrm{mM}$ glutamine (this medium will be referred as 
'standard medium'). After 24-h the standard medium was changed by DMEM:F12 medium containing either $10 \%$ or $0.04 \% \mathrm{FBS}, 100 \mathrm{U} / \mathrm{ml}$ penicillin and $100 \mathrm{U} / \mathrm{ml}$ streptomycin and $6 \mathrm{mM}$ Glutamine (the medium containing $0.04 \%$ FBS will be named 'FBS-deficient' or 'SL-deficient medium'). Then myriocin (SigmaAldrich, St.Louis, MO, US) dissolved in DMSO was added to a final concentration of $2.5 \mu \mathrm{M}$ and cells were cultured for 24,48 or $72 \mathrm{~h}$ before any experiment was performed.

\section{Growth rate and viability tests}

Cell growth. $2.65^{\star} 10^{5}$ cells were seeded in $25 \mathrm{~cm}^{2}$ flasks in standard medium and grown for $24 \mathrm{~h}$ until 15 - $25 \%$ confluence. Then, the standard medium was discarded, cells were washed twice with PBS, and the appropriate medium (standard or deficient, with or without $2.5 \mu \mathrm{M}$ myriocin) was added. Cells were grown for 24,48 or $72 \mathrm{~h}$. Quantification was performed by cell counting with a hemocytometer (BioRad TC20 Automated Cell Counter, Hercules, CA, US).

Viability test. Flow cytometry experiment was performed to evaluate how the myriocin treatment affected cell viability ${ }^{56}$. Cells were stained with Annexin-V-FITC and propidium iodide as indicated in the manual of the annexin V-FITC detection kit (CalbioChem, Darmstadt, Germany) and fluorescence was measured using a FACS Calibur flow cytometer (Becton-Dickinson, Franklin Lakes, NJ, US) as in Ahyayauch et al. ${ }^{57}$. Annexin V-FITC fluorescence intensity was measured in fluorescence channel FL-1 with $\lambda_{\mathrm{ex}}=488 \mathrm{~nm}$ and $\lambda_{\mathrm{em}}=530 \mathrm{~nm}$, while FL-3 was used for propidium iodide detection, with $\lambda_{\mathrm{ex}}=532 \mathrm{~nm}$ and $\lambda_{\mathrm{em}}=561 \mathrm{~nm}$. All measurements were performed in triplicate. Data analysis was performed using Flowing Software 2.

\section{Sample preparation}

Intact cells (whole cells) and PM patches have been used. Intact cells were grown as explained above. $\mathrm{PM}$ patches were isolated by a modification ${ }^{28}$ of the protocol described by Bezrukov et al. ${ }^{27}$. In summary, cells were seeded at approximately $50 \%$ confluence and incubated for $2 \mathrm{~h}$ so that they adhered to the support. After incubation, two washing steps were performed using cold TBS (Tris Buffer Saline: $150 \mathrm{mM}$ $\mathrm{NaCl}, 25 \mathrm{mM}$ Tris- $\mathrm{HCl}, 2 \mathrm{mM} \mathrm{KCl}$ ) to discard non-attached cells. Then, cold distilled water was added for 2 min to induce cell swelling. Mechanical cell disruption was achieved using a pressure stream from a 20$\mathrm{ml}$ syringe coupled to a 19X1-1/2(TW)A needle. In the process, intracellular content was released, while PM stayed attached to the support. Several washing steps were performed to discard the released intracellular content. Purification quality was checked using Di-4-ANEPPDHQ $\left(\lambda_{\mathrm{ex}}=465 \mathrm{~nm}, \lambda_{\mathrm{em}}=635\right.$ $\mathrm{nm}$ ) as a general fluorescent staining, together with organelle-specific fluorophores as described in Monasterio et al. ${ }^{28}$. Images were taken with a Leica TCS SP5 II microscope (Leica Microsystems GmbH, Wetzlar, Germany) at room temperature with ImageJ software. The fluorescence intensities of the various markers were comparatively measured in PM patches and intact cells, so that specific organelle contamination could be estimated.

\section{SM quantification with lysenin}


Lysenin-mCherry expression and purification. The non-toxic monomeric C-terminal domain of the SMspecific toxin, non-toxic- (NT) lysenin, was expressed and purified as described by Carquin et al. ${ }^{58}$. Briefly, the expression plasmid pET28/lysenin encoded NT-lysenin as a fusion protein with an N-terminal 6xHistag followed by the monomeric red fluorescent protein mCherry. The plasmid was expanded in Escherichia coli BL21 (DE3) and the recombinant protein was expressed in lysogeny broth (LB) medium at $16^{\circ} \mathrm{C}$ for $72 \mathrm{~h}$ in the presence of $0.4 \mathrm{mM}$ isopropyl $\beta$-D-thiogalactoside. Bacterial extracts were prepared as described ${ }^{59}$ and the recombinant protein was purified using an Ni-NTA Superflow cartridge (Qiagen, Hilden, Germany) and eluted with imidazol ${ }^{60}$. Fraction analysis by SDS-PAGE revealed recombinant NTlysenin with the expected size $(45 \mathrm{kDa})$. The most enriched fractions were pooled, concentrated, and desalted. The aliquots were stored in $20 \mathrm{mM} \mathrm{NaCl}$ and $25 \mathrm{mM} \mathrm{Hepes} \mathrm{pH} 7.2$ and $5 \%$ glycerol at $-80^{\circ} \mathrm{C}$. Protein concentration was calculated by measuring absorbance at $280 \mathrm{~nm}$.

SM staining and quantification with lysenin-mCherry. SM in whole cells and PM patches was stained with lysenin-mCherry and samples were visualized using a confocal microscopy Nikon D-ECLIPSE C1 (Nikon, Melville, NY, US). Samples were stained with lysenin-mCherry at $100 \mu \mathrm{M}$ prior to visualization. PM patches, but not whole cells, were first stained with $100 \mu \mathrm{M}$ NBD-PE as a control for all-lipid staining. A washing step was performed with PBS, and lysenin-mCherry was added at $100 \mu \mathrm{M}$ final concentration. Whole-cell mCherry signal was also quantified using a FL-3 FACS Calibur flow cytometer (BectonDickinson, Franklin Lakes, NJ, US) with $\lambda_{\mathrm{ex}}=532 \mathrm{~nm}$ and $\lambda_{\mathrm{em}}=561 \mathrm{~nm}$.

\section{Laurdan General Polarization (GP)}

Laurdan is a fluorescence polarity probe whose emission undergoes a spectral shift due to the reorientation of water molecules in the glycerol backbone region of the membrane, and this shift can be correlated to the lipid phase ${ }^{30}$. In the gel phase, when little water is present, laurdan maximum emission is around $440 \mathrm{~nm}$, whereas in the liquid crystalline phase the spectrum is red shifted to around $490 \mathrm{~nm}$. Intact cells and PM patches have been used to compare the laurdan fluorescence of myriocin treated or non-treated $\mathrm{CHO}$ and LY-B cells. Samples were stained with $5 \mu \mathrm{M}$ laurdan (Molecular Probes, Eugene, OR, US) for $5 \mathrm{~min}$ and two PBS washing steps were performed prior to cell visualization.

Image acquisition and analysis. Images were acquired and analysed as described in Monasterio et al. ${ }^{13}$. In summary, a Leica TCS SP5 II microscope (Leica Microsystems GmbH, Wetzlar, Germany) with a 63x water-immersion objective (numerical aperture $N A=1.2$ ) was used and samples were imaged at $512 \mathrm{x}$ 512 pixel and $400 \mathrm{~Hz}$ per scanning line. Equatorial planes were imaged to avoid photoselection effects. A pulsed titanium-sapphire (Mai-Tai Deepsee, Spectra-Physics) laser tuned at $780 \mathrm{~nm}$ was used for twophoton imaging of laurdan-labeled samples. Fluorescence emission was collected by non-descanned (NDD) hybrid detectors, as they offer higher sensitivity compared to descanned photomultipliers. The blue edge of the emission spectrum was collected by NDD 1 at $435 \pm 20 \mathrm{~nm}$ and the red edge by NDD 2 at 500 $\pm 10 \mathrm{~nm}$. Irradiance at the sample plane was $\approx 500 \mathrm{GW} \cdot \mathrm{cm}^{-2}$ for two-photon excitation ${ }^{61}$. 
GP value of samples was calculated using a MATLAB (MathWorks, Natick, MA, US) based software. Images were smooth in each channel with 2 pixel averaging, and the GP value was calculated using the following equation ${ }^{62}$ :

$$
G P=\frac{I_{B}-G \cdot I_{R}}{I_{B}+G \cdot I_{R}}
$$

where $I_{B}$ is the intensity collected by NDD $1, I_{R}$ is the intensity collected by NDD 2, and $G$ is the correction factor. The $\mathrm{G}$ factor is calculated measuring the GP value of the same fluorophore concentration used in sample staining, dissolved in this case in pure $\mathrm{DMSO}^{31}$. The region of interest, i.e. the PM, was selected.

\section{Atomic Force Microscopy}

Topographic images and force spectroscopy analysis of PM patches were performed. PM patches were prepared as previously described ${ }^{27,28}$, using this time polylysine-coated mica slips instead of glassbottom dishes. PM patches were first stained using Di-4-ANEPPQHD to allow detection on the mica slip.

Samples were measured as described in Monasterio et al. ${ }^{13}$. In summary, contact mode AFM imaging has been used to study bilayer topography, looking at possible lateral segregation effects through bilayer thickness analysis. A NanoWizard II AFM (JPK Instruments, Berlin, Germany) was used to perform topographic measurements under contact mode scanning (constant vertical deflection). For measurements, the AFM was coupled to a Leica microscope and mounted onto a Halcyonics Micro 40 anti-vibration table (Halcyonics, Inc., Menlo Park, CA, US) and inside an acoustic enclosure (JPK Instruments, Berlin, Germany) ${ }^{63}$. V-shaped MLCT $\mathrm{Si}_{3} \mathrm{~N}_{4}$ cantilevers (Bruker, Billerica, MA, US) with nominal spring constants of 0.1 or $0.5 \mathrm{~N} / \mathrm{m}$. The sample thickness was estimated by cross-section height analysis ${ }^{64}$.

For Force Spectroscopy, V-shaped MLCT $\mathrm{Si}_{3} \mathrm{~N}_{4}$ cantilevers (Bruker, Billerica, MA, US) with nominal spring constants of 0.1 or $0.5 \mathrm{~N} / \mathrm{m}$ were individually calibrated in a lipid-free mica substrate in assay buffer using the thermal noise method. After proper bilayer area localization by means of AFM topography and direct epifluorescence microscopy, force spectroscopy was performed at a speed of $1 \mu \mathrm{m} / \mathrm{s}$. Force steps were determined for each of the indentation curves as reproducible jumps within the extended traces. At least three independent sample preparations were scanned for each case and 50-100 curves were measured in each sample.

\section{Mass spectroscopic analysis}

Mass spectroscopic analysis was performed essentially as described in Monasterio et al. ${ }^{28}$. A methodological summary follows. 
Sample treatment. Lipid extraction was performed using a modified methyl tert-butyl ether (MTBE) protocol ${ }^{65}$. Briefly, cells or PM patches were washed with cold PBS and scraped off in $500 \mu$ cold PBS on ice. The suspensions were transferred to a $2 \mathrm{ml}$ tube and spun down at $3200 \mathrm{rpm}$ for $5 \mathrm{~min}$ at $4^{\circ} \mathrm{C}$. After removing the PBS, samples were stored at $-20^{\circ} \mathrm{C}$ or directly used for further extraction. Then, $360 \mu \mathrm{l}$ methanol was added and vortexed. A mixture of lipid standards (see table 1) was added and samples were vortexed for 10 min at $4^{\circ} \mathrm{C}$ using a Cell Disruptor Genie (Scientific Industries, Inc., Bohemia, NY, US). MTBE $(1.2 \mathrm{ml})$ was then added and the samples were incubated for $1 \mathrm{~h}$ at room temperature with shaking (750 rpm). Phase separation was induced by adding $200 \mu \mathrm{l} \mathrm{H} \mathrm{H}_{2} \mathrm{O}$. After $10 \mathrm{~min}$ incubation at room temperature, the samples were centrifuged at $1,000 \mathrm{xg}$ for $10 \mathrm{~min}$. The upper (organic) phase was transferred to a 13-mm screw-cap glass tube and the lower phase was extracted with $400 \mu \mathrm{l}$ artificial upper phase (MTBE/methanol/water (10:3:1.5, v/v/v)). The two upper phases were combined and the total lipid extract was divided in 3 equal aliquots (one for phospholipids (TL), one for sterols (S) in 2-ml amber vials, and one for SL detection in a 13-mm glass tube) and dried in a Centrivap at $50^{\circ} \mathrm{C}$ or under a nitrogen flow. The SL aliquot was deacylated by methylamine treatment (Clarke method) to remove glycerophospholipids. $0.5 \mathrm{ml}$ monomethylamine reagent $\left[\mathrm{MeOH} / \mathrm{H}_{2} \mathrm{O} / \mathrm{n}\right.$-butanol/methylamine solution (4:3:1:5 v/v)] was added to the dried lipid, followed by sonication ( $5 \mathrm{~min}$ ). Samples were then mixed and incubated for $1 \mathrm{~h}$ at $53^{\circ} \mathrm{C}$ and dried (as above). The monomethylamine-treated lipids were desalted by $\mathrm{n}$ butanol extraction. $300 \mu \mathrm{H}_{2} \mathrm{O}$-saturated n-butanol was added to the dried lipids. The sample was vortexed, sonicated for $5 \mathrm{~min}$ and $150 \mu \mathrm{l}$ MS-grade water was added. The mixture was vortexed thoroughly and centrifuged at $3200 \mathrm{xg}$ for $10 \mathrm{~min}$. The upper phase was transferred to a 2-ml amber vial. The lower phase was extracted twice more with $300 \mu \mathrm{l} \mathrm{H}_{2} \mathrm{O}$-saturated n-butanol and the upper phases were combined and dried (as above).

Glycerophospholipid and sphingolipid detection on a Triple Quadrupole Mass Spectrometer. TL and SL aliquots were resuspended in $250 \mu \mathrm{l}$ chloroform/methanol (1:1 v/v) (LC-MS/HPLC grade) and sonicated for $5 \mathrm{~min}$. The samples were pipetted in a 96-well plate (final volume $=100 \mu \mathrm{l})$. The TL were diluted 1:4 in negative-mode solvent (chloroform/methanol (1:2) $+5 \mathrm{mM}$ ammonium acetate) and 1:10 in positivemode solvent (chloroform/methanol/water $(2: 7: 1 \mathrm{v} / \mathrm{v})+5 \mathrm{mM}$ ammonium acetate). The SL were diluted 1:10 in positive-mode solvent and infused onto the mass spectrometer. Tandem mass spectrometry for the identification and quantification of SL molecular species was performed using Multiple Reaction Monitoring (MRM) with a TSQ Vantage Triple Stage Quadrupole Mass Spectrometer (Thermofisher Scientific, Waltham, MA, US) equipped with a robotic nanoflow ion source, Nanomate HD (Advion Biosciences, Ithaca, NY, US). The collision energy was optimized for each lipid class. The detection conditions for each lipid class are listed below (table 1). Cer species were also quantified with a loss of water in the first quadrupole. Each biological replica was read in 2 technical replicas (TR). Each TR comprised 3 measurements for each transition. Lipid concentrations were calculated relative to the relevant internal standards and then normalized to the total lipid content of each lipid extract ( $\mathrm{mol} \%)$. Lipid signals were not subjected to de-isotoping.

\section{Gas chromatography-mass spectrometry for cholesterol assay}

Page $14 / 24$ 
Lipid extracts were analyzed by GC-MS as described previously ${ }^{66}$. Briefly, samples were injected into a VARIAN CP-3800 gas chromatograph equipped with a FactorFour Capillary Column VF-5ms $15 \mathrm{~m} \times 0.32$ $\mathrm{mm}$ i.d. $\mathrm{DF}=0.10$, and analyzed in a Varian $320 \mathrm{MS}$ triple quadrupole with electron energy set to $-70 \mathrm{eV}$ at $250^{\circ} \mathrm{C}$ (Varian, Palo Alto, CA, US). Samples were applied to the column oven at $45^{\circ} \mathrm{C}$, held for $4 \mathrm{~min}$, then raised to $195^{\circ} \mathrm{C}\left(20^{\circ} \mathrm{C} / \mathrm{min}\right)$. Sterols were eluted with a linear gradient from 195 to $230^{\circ} \mathrm{C}\left(4^{\circ} \mathrm{C} / \mathrm{min}\right)$, followed by rising to $320^{\circ} \mathrm{C}\left(10^{\circ} \mathrm{C} / \mathrm{min}\right)$. Cholesterol was identified by its retention time (compared with an ergosterol standard) and fragmentation patterns, which were compared with the NIST library.

\section{Declarations}

\section{Acknowledgements}

The authors are grateful to Dr. X. Contreras for his critical reading of the manuscript. This work was supported in part by the Spanish Ministerio de Ciencia e Innovación ( $\mathrm{MCl})$, Agencia Estatal de Investigación (AEI) and Fondo Europeo de Desarrollo Regional (FEDER) (grant No. PGC2018-099857-B100), by the Basque Government (Grants No. IT1264-19, IT1196-19 and IT1270-19), by the Fundación Biofísica Bizkaia and by the Basque Excellence Research Centre (BERC) program of the Basque Government, and by the Swiss National Science Foundation (310030-184949).

\section{Author contributions}

B.G.M. contributed to the design and analysis of the experiments, and performed most of them, A.B.G.A. performed the AFM experiments, N.J.R. carried out the lipidomic studies. F.M.G., H.R. and A.A. designed the experimental part and analyzed the results, F.M.G. wrote a first draft of the manuscript, all authors contributed to the manuscript in final form, H.R. and A.A. reviewed the manuscript in its final form.

\section{Competing interests}

The authors declare no competing interests.

\section{Publisher's note}

Springer Nature remains neutral with regard to jurisdictional claims in published maps and institutional affiliations.

\section{Supplementary information}

is available for this paper at

\section{References}

1. lessi, E. et al. On the role of sphingolipids in cell survival and death. Int. Rev. Cell Mol. Biol. 351, 149195 (2020). 
2. Spiegel, S. \& Milstien, S. Exogenous and intracellularly generated sphingosine 1-phosphate can regulate cellular processes by divergent pathways. Biochem. Soc. Trans. 31, 1216-1219 (2003).

3. Tomassini, B. \& Testi, R. Mitochondria as sensors of sphingolipids. Biochimie. 84, 123-129 (2002).

4. Luberto, C., Kraveka, J. M. \& Hannun, Y. A. Ceramide regulation of apoptosis versus differentiation: A walk on a fine line. Lessons from neurobiology. Neurochem. Res. 27, 609-617 (2002).

5. Sharma, N., He, Q. \& Sharma, R. P. Sphingosine kinase activity confers resistance to apoptosis by fumonisin B1 in human embryonic kidney (HEK-293) cells. Chem. Biol. Interact. 151, 33-42 (2004).

6. Kolesnick, R. The therapeutic potential of modulating the ceramide/ sphingomyelin pathway. J. Clin. Invest. 1, 3-8 (2002).

7. Pinto, W. et al. Sphingolipid long-chain-base auxotrophs of Saccharomyces cerevisiae: genetics, physiology, and a method for their selection. J. Bacteriol. 174, 2565-2574 (1992).

8. Hanada, K. et al. Mammalian cell mutants resistant to a sphingomyelin-directed cytolysin. J. Biol. Chem. 273, 33787-33794 (1998).

9. Nakamura, H. et al. Sphingomyelin regulates the activity of secretory phospholipase A2 in the plasma membrane. J. Cell. Biochem. 116, 1898-1907 (2015).

10. Mise, K. et al. Involvement of ganglioside GM3 in G2/M cell cycle arrest of human monocytic cells induced by Actinobacillus actinomycetemcomitans cytolethal distending toxin. Infect. Immun. 73, 4846-4852 (2005).

11. Han, G. et al. Identification of small subunits of mammalian serine palmitoyltransferase that confer distinct acyl-CoA substrate specificities. Proc. Natl. Acad. Sci. 106, 9931-9931(2009).

12. Bejaoui, K. et al. Hereditary sensory neuropathy type 1 mutations confer dominant negative effects on serine palmitoyltransferase, critical for sphingolipid synthesis. J. Clin. Invest. 110, 1301-1308 (2002).

13. Monasterio, B. G. et al. CHO/LY-B cell growth under limiting sphingolipid supply: correlation between lipid composition and biophysical properties of sphingolipid-restricted cell membranes. bioRxiv 2020.07.05.188474(2020). doi:10.1101/2020.07.05.188474

14. Gupta, B. \& Tiwary, A. K. Role of sphingosine synthesis inhibition in transcutaneous delivery of levodopa. Int. J. Pharm. 238, 43-50 (2002).

15. Hinkovska-Galcheva, V., Boxer, L., Mansfield, P. J., Schreiber, A. D. \& Shayman, J. A. Enhanced phagocytosis through inhibition of de novo ceramide synthesis. J. Biol. Chem. 278, 974-982 (2003).

16. Zweerink, M. M., Edison, A. M., Wells, G. B., Pinto, W. \& Lester, R. L. Characterization of a novel, potent, and specific inhibitor of serine palmitoyltransferase. J. Biol. Chem. 267, 25032-25038 (1992).

17. Chalfant, C. E. et al. FAS activation induces dephosphorylation of SR proteins: Dependence on the de novo generation of ceramide and activation of protein phosphatase 1. J. Biol. Chem. 276, 4484844855 (2001).

18. Solomon, J. C., Sharma, K., Wei, L. X., Fujita, T. \& Shi, Y. F. A novel role for sphingolipid intermediates in activation-induced cell death in T cells. Cell Death Differ. 10, 193-202 (2003). 
19. Li, H. et al. Myriocin, a serine palmitoyltransferase inhibitor, increases melanin synthesis in Mel-Ab cells and a skin equivalent model. Pharmazie. 69, 187-191 (2014).

20. Kluepfel, D. et al. Myriocin, a new antifungal antibiotic from Myriococcum arbomyces. J. Antibiot. (Tokyo). 22, 109-115 (1972).

21. Gupta, M., Mahajan, A. \& Babita, Gupta, S. T. A. Inhibition of skin sphingosine synthesis: enhanced percutaneous permeation of 5-fluorouracil. Pharmazie. 59, 212-216 (2004).

22. Kroesen, B. J. et al. BcR-induced apoptosis involves differential regulation of C16 and C24-ceramide formation and sphingolipid-dependent activation of the proteasome. J. Biol. Chem. 278, 1472314731 (2003).

23. Mao-Qiang, M., Elias, P. M. \& Feingold, K. R. Fatty acids are required for epidermal permeability barrier function. J. Clin. Invest. 92, 791-798 (1993).

24. Holleran, W. et al. Regulation of epidermal sphingolipid synthesis by permeability barrier function. $J$. Lipid. Res. 32, 1151-1158 (1991).

25. Feingold, K. The regulation of epidermal lipid synthesis by permeability barrier requirements. Crit Rev Ther Drug Carr. Syst. 8, 193-210 (1991).

26. Jiménez-Rojo, N. et al. Conserved functions of ether lipids and sphingolipids in the early secretory pathway. Curr. Biol. 30, 3775-3787 (2020).

27. Bezrukov, L., Blank, P. S., Polozov, I. V. \& Zimmerberg, J. An adhesion-based method for plasma membrane isolation: Evaluating cholesterol extraction from cells and their membranes. Anal. Biochem. 394, 171-176 (2009).

28. Monasterio, B. G. et al. Patches and blebs: A comparative study of the composition and biophysical properties of two plasma membrane preparations from CHO cells. Int. J. Mol. Sci. 21, 2643 (2020).

29. Contreras, X., Sot, J., Alonso, A. \& Goñi, F. M. La esfingosina aumenta la permeabilidad del modelo y las membranas celulares. Biophys J. 90, 4085-4092 (2006).

30. Krasnowska, E. K., Gratton, E. \& Parasassi, T. Prodan as a membrane surface fluorescence probe: Partitioning between water and phospholipid phases. Biophys. J. 74, 1984-1993 (1998).

31. Owen, D. M., Rentero, C., Magenau, A., Abu-Siniyeh, A. \& Gaus, K. Quantitative imaging of membrane lipid order in cells and organisms. Nat. Prot. 7, 24-35 (2012).

32. Umagai, I. Z. K., Keda, K. A. I., Obayashi, T. O. K. \& Ada, H. I. W. Imaging by atomic force microscopy of the plasma membrane of prestin-transfected Chinese Hamster Ovary cells. J. Assoc. Res. Oto. 278, 267-278 (2006).

33. van Meer, G., Voelker, R., Feigenson, W. \& D. \& G. Membrane lipids: where they are and how they behave. Nat. Rev. Mol. Cell. Biol. 9, 112-124 (2008).

34. Miyake, Y., Kozutsumi, Y., Nakamura, S., Fujita, T. \& Kawasaki, T. Serine palmitoyltransferase is the primary target of a sphingosine-like immunosuppressant, ISP-1/myriocin. Biochem. Biophys. Res. Commun. 211, 396-403 (1995). 
35. Hannun, C. \& Linardic, Y. Sphingolipid breakdown products: Anti-proliferative and tumor-suppressor lipids. Biochim Biophys Acta. 1154, 223-236 (1993).

36. Cartier, A. \& Hla, T. Sphingosine 1-phosphate: Lipid signaling in pathology and therapy. Science. 366, eaar5551 (2019).

37. Yatomi, Y. et al. Dimethylsphingosine inhibition of sphingosine kinase and sphingosine-1-phosphate activity in human platelets. Biochemistry. 35, 626-633 (1996).

38. Yoshino, O. et al. Sphingosine 1 phosphate (S1P) increased IL-6 expression and cell growth in endometriotic cells. Reprod Sci. 26, 1460-1467 (2019).

39. Lidgerwood, G., Pitson, S., Bonder, C. \& Pébay, A. Roles of lysophosphatidic acid and sphingosine-1phosphate in stem cell biology. Prog Lipid Res. 72, 42-54 (2018).

40. Spiegel, S. et al. Sphingosine-1-phosphate in cell growth and cell death. Ann N Y Acad Sci. 19, 11-28 (1998).

41. Hanada, K., Nishijima, M., Fujita, T. \& Kobayashi, S. Specificity of inhibitors of serine palmitoyltransferase (SPT), a key enzyme in sphingolipid biosynthesis, in intact cells. A novel evaluation system using an SPT-defective mammalian cell mutant. Biochem Pharmacol. 59, 12111216 (2000).

42. Merrill, A. H. J. et al. Sphingolipids-the enigmatic lipid class: biochemistry, physiology, and pathophysiology. Toxicol. Appl. Pharmacol. 142, 208-222 (1997).

43. Meer, G., Van, Wolthoorn, J. \& Degroote, S. The fate and function of glycosphingolipid glucosylceramide. Philos. T. R. Soc. B. 358, 869-873 (2003).

44. Ziulkoski, A. L., Zimmer, A. R. \& Guma, F. C. R. De novo synthesis and recycling pathways of sphingomyelin in rat sertoli cells. Biochem. Bioph. Res. CO. 281, 971-975 (2001).

45. Frisz, J. F. et al. Direct chemical evidence for sphingolipid domains in the plasma membranes of fibroblasts. Proc. Natl. Acad. Sci. 110, E613-E622(2013).

46. Frisz, J. F. et al. Sphingolipid domains in the plasma membranes of fibroblasts are not enriched with cholesterol. J. Biol. Chem. 288, 16855-16861 (2013).

47. Nicovich, P. R., Kwiatek, J. M., Ma, Y., Benda, A. \& Gaus, K. FSCS reveals the complexity of lipid domain dynamics in the plasma membrane of live cells. Biophys. J. 114, 2855-2864 (2018).

48. Stark, G. Multifunctional proteins: one gene - more than one enzyme. Trends. Biochem. Sci. 2, 6466 (1997).

49. Jeffery, C. Multifunctional proteins: examples of gene sharing. Ann Med. 35, 28-35 (2003).

50. Espinosa-Cantú, A., Cruz-Bonilla, E., Noda-Garcia, L. \& DeLuna, A. Multiple forms of multifunctional proteins in health and disease. Front Cell Dev Biol. 8, 451 (2020).

51. Hojjati, M. et al. Effect of myriocin on plasma sphingolipid metabolism and atherosclerosis in apoEdeficient mice. J. Biol. Chem. 280, 10284-10289 (2005).

52. Park, T., Rosebury, W., Kindt, E., Kowala, M. \& Panek, R. Serine palmitoyltransferase inhibitor myriocin induces the regression of atherosclerotic plaques in hyperlipidemic ApoE-deficient mice. Pharmacol. 
Res. 58, 45-51 (2008).

53. Holland, W. et al. Inhibition of ceramide synthesis ameliorates glucocorticoid-, saturated-fat-, and obesity-induced insulin resistance. Cell Metab. 5, 167-179 (2007).

54. Kurek, K. et al. Inhibition of ceramide de novo synthesis reduces liver lipid accumulation in rats with nonalcoholic fatty liver disease. Liver Int. 34, 1074-1083 (2013).

55. Lin, G. et al. Phospholipase PLA2G6, a parkinsonism-associated gene, affects Vps26 and Vps35, retromer function, and Ceramice levels, similar to a-synuclein gain. Cell Metab. 28, 605-618 (2018).

56. Galisteo-González, F., Monasterio, B. G., Gil, D., Valle, M. \& Goñi, F. Photoacoustic effect applied on model membranes and living cells: direct observation with multiphoton excitation microscopy and long-term viability analysis. Sci. Rep. 10, 299 (2020).

57. Ahyayauch, H. et al. Pb (II) induces scramblase activation and ceramide-domain generation in red blood cells. Sci. Rep. 8, 1-17 (2018).

58. Carquin, M. et al. Endogenous sphingomyelin segregates into submicrometric domains in the living erythrocyte membrane. J. Lipid Res. 55, 1331-1342 (2014).

59. Maliekal, P., Vertommen, D., Delpierre, G. \& Van Schaftingen, E. Identification of the sequence encoding N -acetylneuraminate-9-phosphate phosphatase. Glycobiol. 16, 165-172 (2006).

60. Veiga-da-Cunha, M., Hadi, F., Balligand, T., Stroobant, V. \& Van Schaftingen, E. Molecular identification of hydroxylysine kinase and of ammoniophospholyases acting on 5-Phosphohydroxy- $\mathrm{L}$-lysine and phosphoethanolamine. J. Biol. Chem. 287, 7246-7255 (2012).

61. Parasassi, T. \& Gratton, E. Two-photon fluorescence microscopy of laurdan generalized polarization domains in model and natural membranes. Biophys. J. 72, 2413-2429 (1997).

62. Carravilla, P., Nieva, J. L., Goñi, F. M., Requejo-isidro, J. \& Huarte, N. Two-photon laurdan studies of the ternary lipid mixture DOPC:SM:Cholesterol reveal a single liquid phase at Sphingomyelin:Cholesterol ratios lower than 1. Langmuir. 31, 2808-2817 (2015).

63. Monasterio, B. G. et al. Coating graphene oxide with lipid bilayers greatly decreases its hemolytic properties. Langmuir. 33, 8181-8191 (2017).

64. García-Arribas, A. B., Busto, J. V., Alonso, A. \& Goñi, F. M. Atomic force microscopy characterization of palmitoylceramide and cholesterol effects on phospholipid bilayers: A topographic and nanomechanical study. Langmuir. 31, 3135-3145 (2015).

65. Guri, Y. et al. mTORC2 Promotes tumorigenesis via lipid synthesis. Cancer cell. 32, 807-823 (2017).

66. Guan, X. L., Riezman, I., Wenk, M. R. \& Riezman, H. Yeast lipid analysis and quantification by mass spectrometry. Methods Enzym. 470, 369-391 (2010).

\section{Tables}

Table 1. MS detection conditions for the different lipid classes. 


\begin{tabular}{|c|c|c|c|c|c|}
\hline Lipid Class & Standard & Polarity & Mode & $\mathrm{m} / \mathrm{z}$ ion & $\begin{array}{l}\text { Collision } \\
\text { Energy }\end{array}$ \\
\hline Phosphatidylcholine $[\mathrm{M}+\mathrm{H}]^{+}$ & DLPC & + & Product ion & 184.07 & 30 \\
\hline $\begin{array}{l}\text { Phosphatidylethanolamine } \\
{[\mathrm{M}+\mathrm{H}]^{+}}\end{array}$ & PE31:1 & + & $\begin{array}{l}\text { Neutral ion } \\
\text { loss }\end{array}$ & 141.02 & 20 \\
\hline Phosphatidylinositol [M-H] $]^{-}$ & $\mathrm{PI} 31: 1$ & - & Product ion & 241.01 & 44 \\
\hline Phosphatidylserine $[\mathrm{M}-\mathrm{H}]^{-}$ & PS31:1 & - & $\begin{array}{l}\text { Neutral ion } \\
\text { loss }\end{array}$ & 87.03 & 23 \\
\hline Cardiolipin $[\mathrm{M}-2 \mathrm{H}]^{2-}$ & CL56:0 & - & Product ion & $\begin{array}{l}\text { acyl } \\
\text { chain }\end{array}$ & 32 \\
\hline Ceramide $[\mathrm{M}+\mathrm{H}]^{+}$ & C17Cer & + & Product ion & 264.34 & 25 \\
\hline Dihydroceramide $[\mathrm{M}+\mathrm{H}]^{+}$ & C17Cer & + & Product ion & 266.40 & 25 \\
\hline Hexosylceramide $[\mathrm{M}+\mathrm{H}]^{+}$ & C8GC & + & Product ion & 264.34 & 30 \\
\hline Hexosyldihydroceramide $[\mathrm{M}+\mathrm{H}]^{+}$ & C8GC & + & Product ion & 266.40 & 30 \\
\hline Sphingomyelin $[\mathrm{M}+\mathrm{H}]^{+}$ & C12SM & + & Product ion & 184.07 & 26 \\
\hline
\end{tabular}

Table 2. Myriocin effect on cholesterol concentration in whole cell or plasma membrane lipid extracts from $\mathrm{CHO}$ or $\mathrm{LY}-\mathrm{B}$ cells grown under limiting SL concentration.

Results are given as mole percent of total lipids in sample. Average \pm S.D. $(n=3)$.

\begin{tabular}{|lllll|}
\hline Cell type & [FBS] & Myriocin & $\begin{array}{l}\text { Mole \% } \\
\text { Whole cells }\end{array}$ & $\begin{array}{l}\text { Mole \% } \\
\text { PM patches }\end{array}$ \\
\hline CHO & $10 \%$ & - & $3.12 \pm 0.17^{\star}$ & $5.91 \pm 0.29^{\star}$ \\
\hline CHO & $0.04 \%$ & - & $1.56 \pm 0.19$ & $3.12 \pm 0.20$ \\
\hline CHO & $0.04 \%$ & $2.5 \mu \mathrm{M}$ & $1.36 \pm 0.07$ & $3.43 \pm 0.42$ \\
\hline LY-B & $10 \%$ & - & $3.05 \pm 0.13^{\star}$ & $8.65 \pm 0.90^{\star}$ \\
\hline LY-B & $0.04 \%$ & - & $1.22 \pm 0.01$ & $3.85 \pm 0.51$ \\
\hline LY-B & $0.04 \%$ & $2.5 \mu \mathrm{M}$ & $1.26 \pm 0.03$ & $3.65 \pm 0.10$ \\
\hline
\end{tabular}

${ }^{*}$ Results taken from Monasterio et al. ${ }^{13}$ 


\section{Figures}

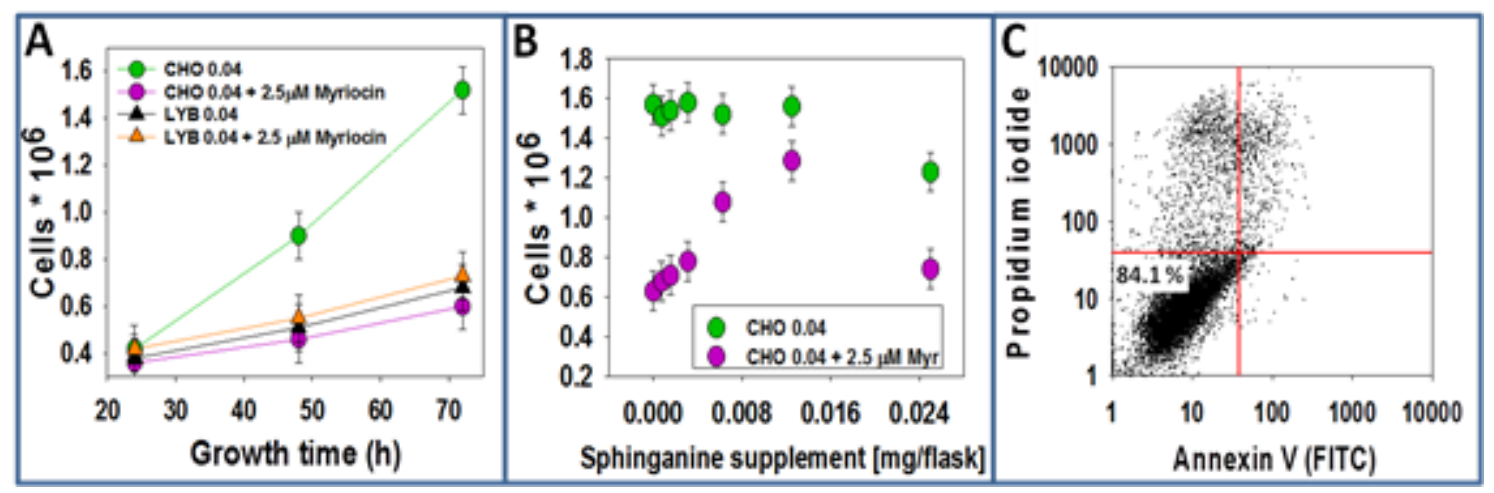

\section{Figure 1}

Myriocin-treated $\mathrm{CHO}$ and $\mathrm{LY}-\mathrm{B}$ cell growth. (A) $\mathrm{LY}-\mathrm{B}$ and $\mathrm{CHO}$ cell growth as a function of time in sphingolipid-deficient (0.04\% FBS) medium, plus/minus $2.5 \mu \mathrm{M}$ myriocin. (B) Myriocin-treated and nontreated $\mathrm{CHO}$ cell growth after $72 \mathrm{~h}$ in sphingolipid-deficient medium supplemented with Sph (seeded cells: $0.25 * 106$ ). (C) FACS assessment of cell viability of $\mathrm{CHO}$ cells after $72 \mathrm{~h}$ in sphingolipid-deficient medium plus $2.5 \mu \mathrm{M}$ myriocin.
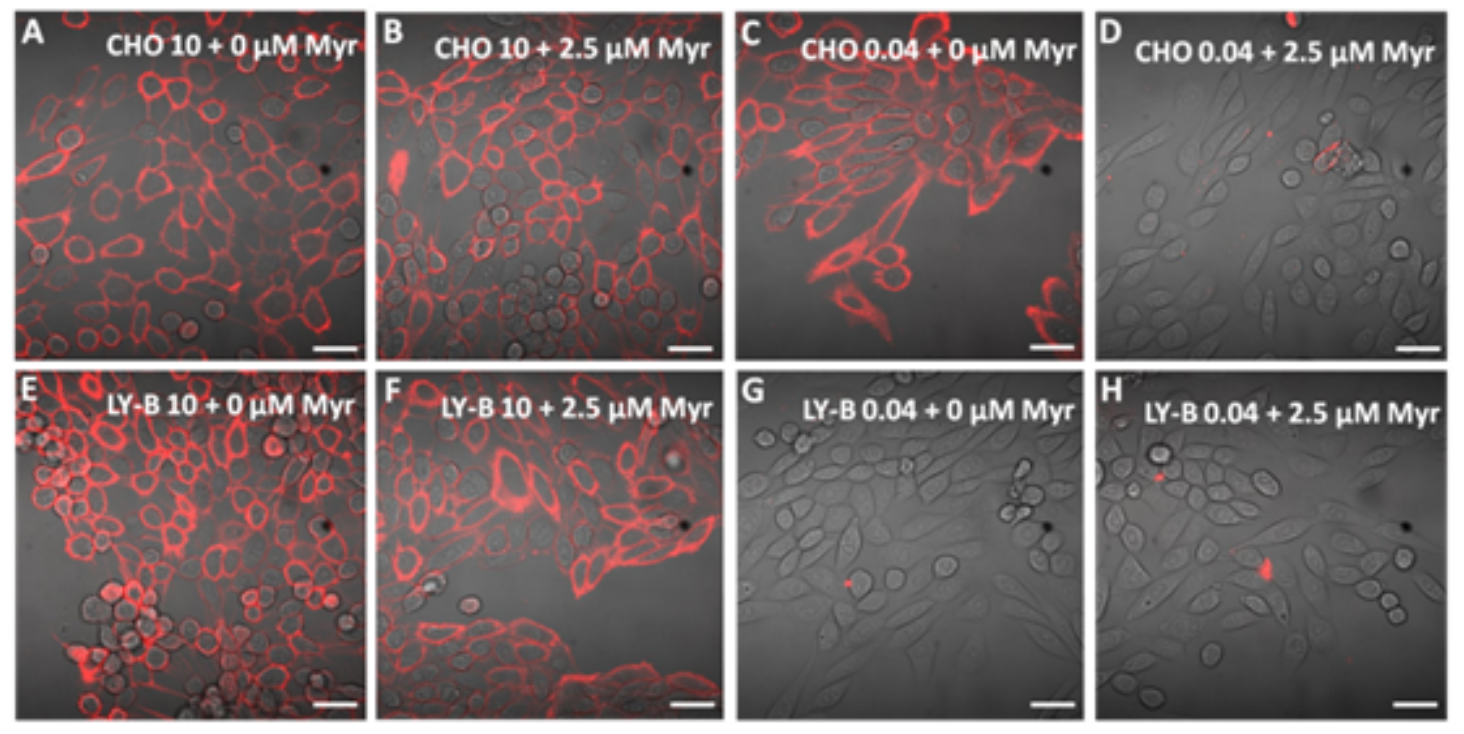

\section{Figure 2}

mCherry-Lysenin-stained myriocin-treated or non-treated cells after $72 \mathrm{~h}$ growth. Non-treated $(\mathrm{A})$ and myriocin-treated (B) CHO cells in standard medium. Non-treated (C) and myriocin-treated (D) $\mathrm{CHO}$ cells in deficient medium. Non-treated (E) and myriocin-treated (F) LY-B cells in standard medium. Non-treated (G) and myriocin-treated $(\mathrm{H}) \mathrm{LY}$-B cells in deficient medium. Bar $=75 \mu \mathrm{m}$. 

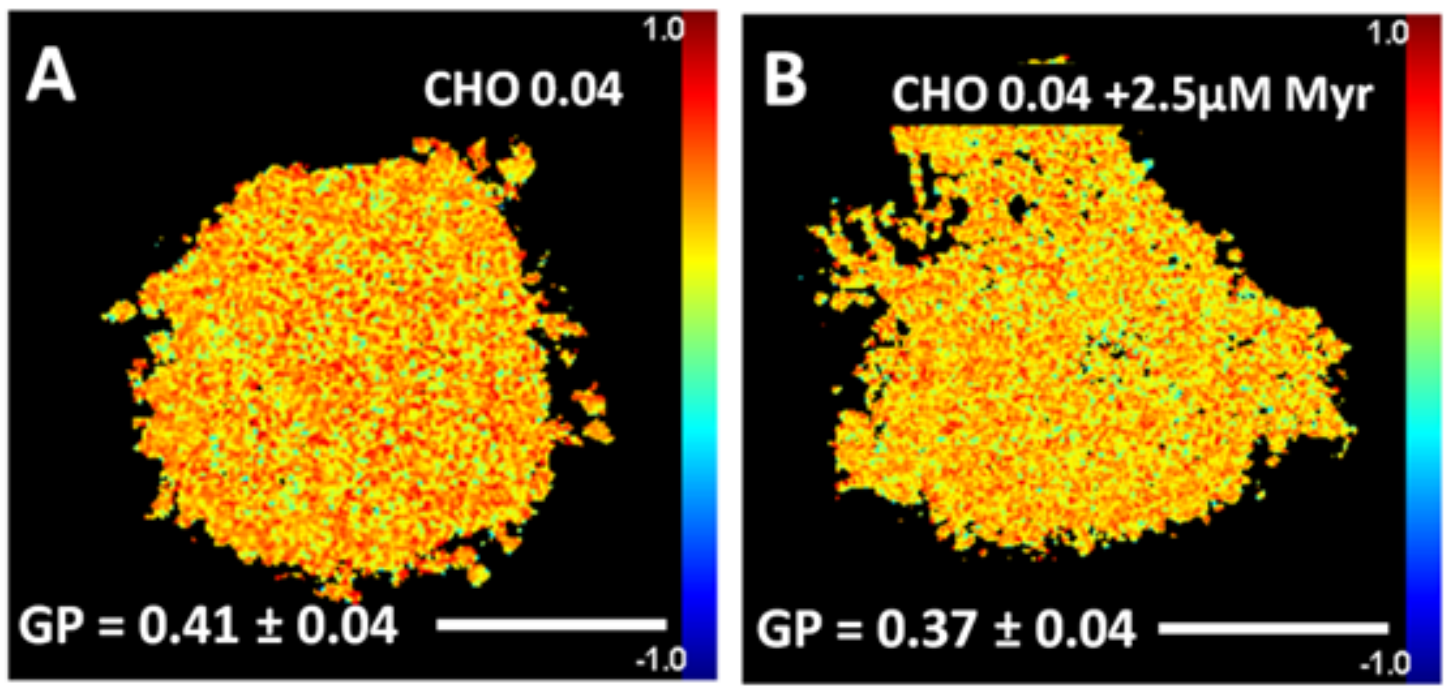

Figure 3

Two-photon microscopy images of PM patches stained with laurdan for GP measurements. PM patches of non-treated (A) and myriocin-treated (B) CHO cells grown in deficient medium. GP are given as average values \pm S.D. $(n=150)$. Statistical significance was calculated with ANOVA or Student's t-test, with similar results: $p=0.03$. Bar $=30 \mu \mathrm{m}$.
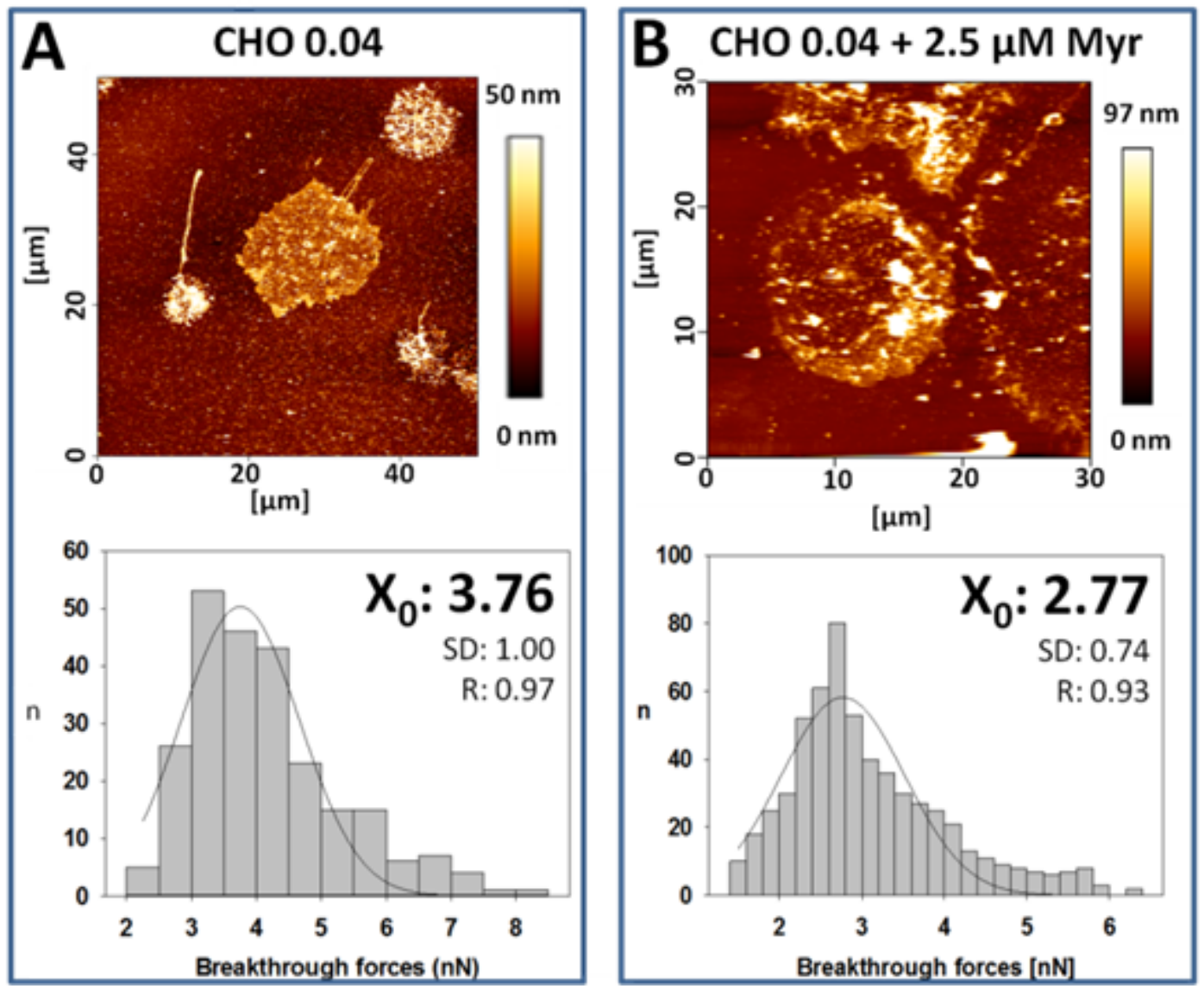

Figure 4 
Topographic image and breakthrough force distributions of PM patches. PM patches from non-treated (A) and myriocin-treated (B) $\mathrm{CHO}$ cells grown in deficient medium. Statistical significance was calculated with ANOVA or Student's t-test, with similar results: $p=0.0008$.
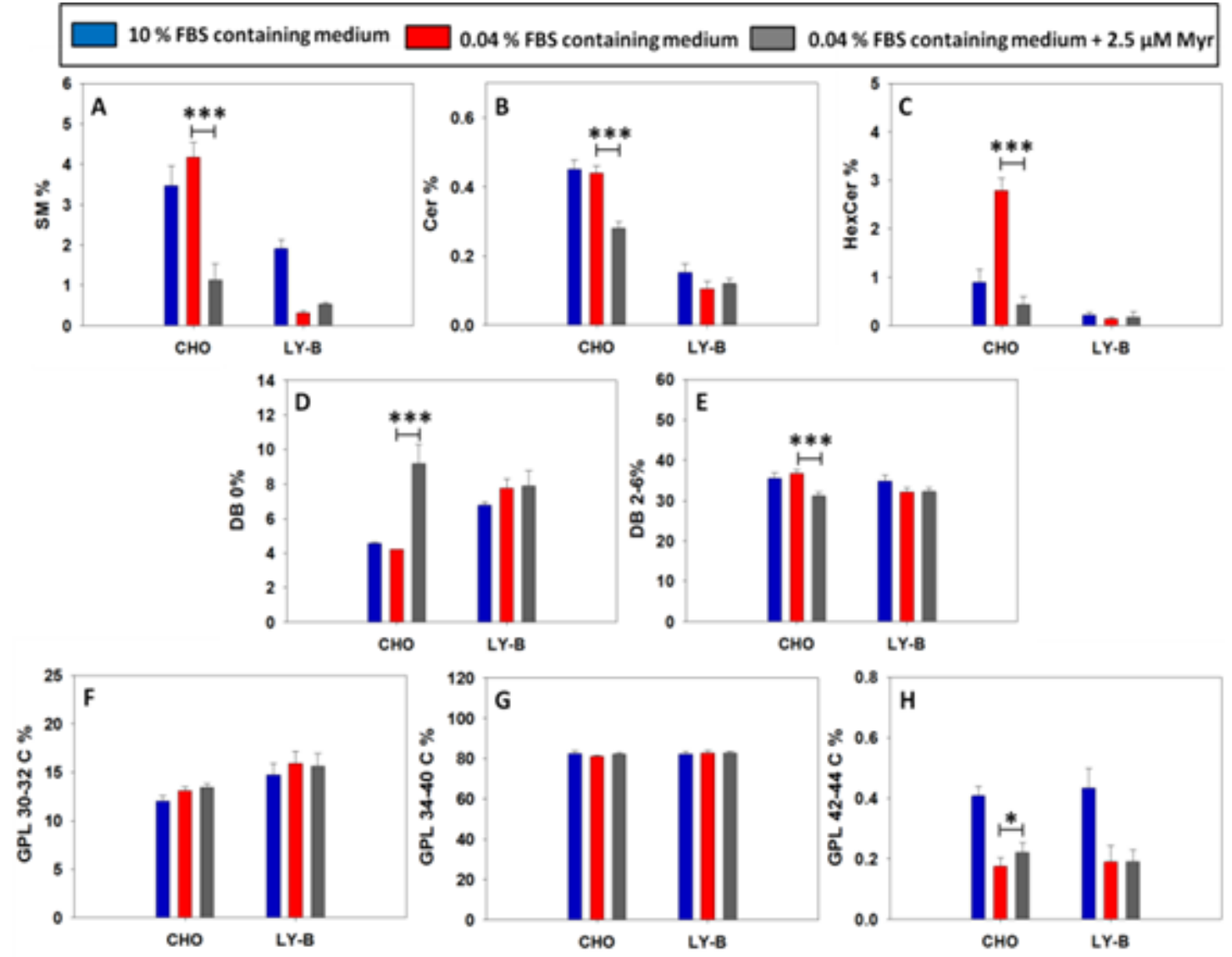

Figure 5

Myriocin treatment effects on the lipid composition of CHO ad LY-B PM patches. Total SM (A), Cer (B) and HexCer (C). Fully saturated (DB = double bond) (D) and polyunsaturated (E) GPL. Short-chain (3032C) (F), long-chain (34-40C) (G) and very-long chain (42-44C) GPL (H). Only selected lipids are included in the figure, a comprehensive description of the various lipid compositions can be seen in the Supplementary Material Table S1. $\mathrm{n}=3$. Statistical significance was calculated with ANOVA or Student's ttest, with similar results. Significance: $\left({ }^{\star}\right) p<0.05 ;\left(^{\star \star \star}\right) p<0.001$. 

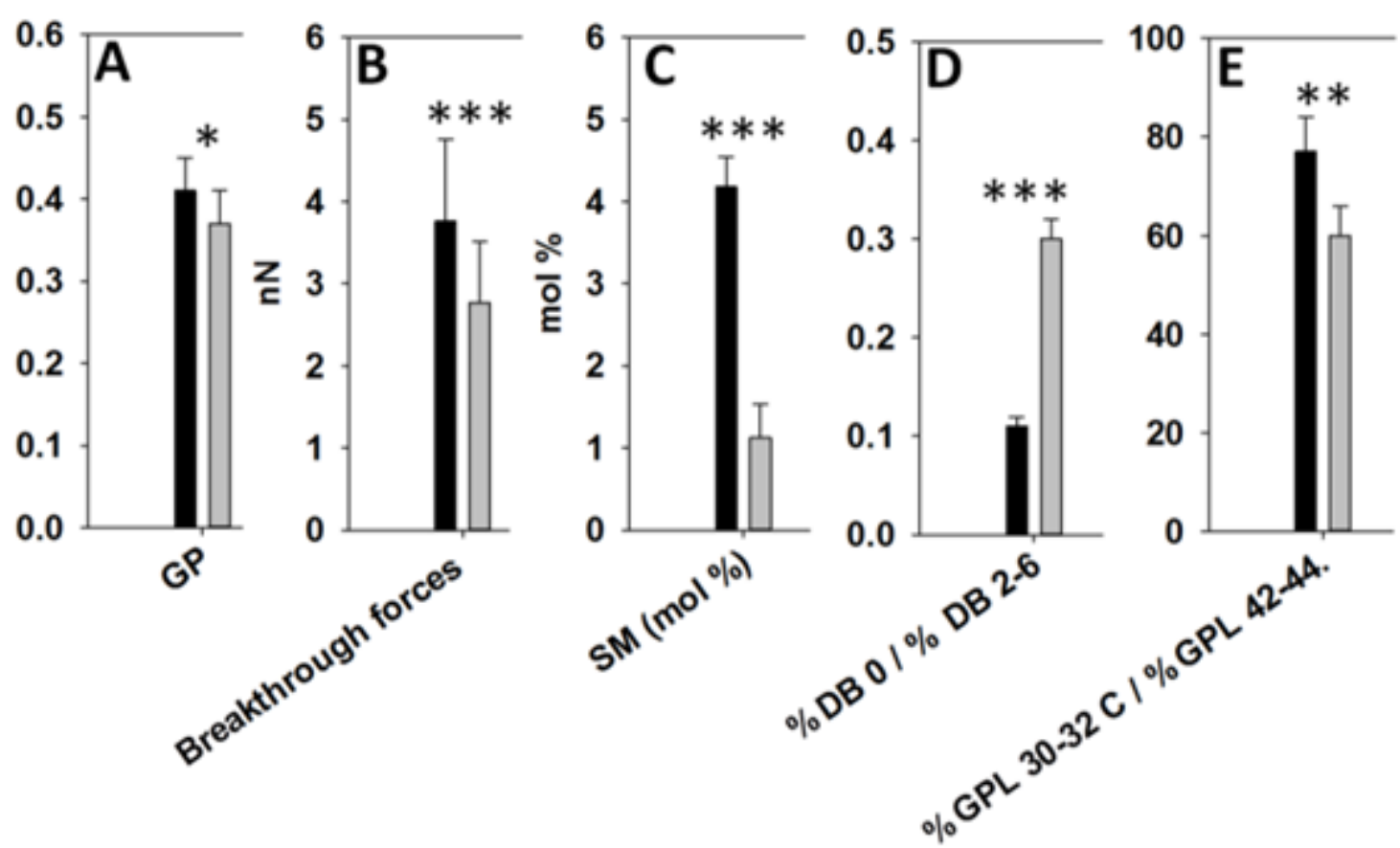

Figure 6

A correlative presentation of myriocin effects on the plasma membranes of $\mathrm{CHO}$ cells grown on SLdeficient medium. Black bars: control, non-myriocin treated cells; grey bars: myriocin-treated cells. (A) Laurdan general polarization in PM patches (data from Fig. 3). (B) Bilayer breakthrough forces obtained by AFM in the force-spectroscopy mode (data from Fig. 4). (C) Mole percent SM contents in PM patches (data from Table S1 and Fig. 5A). (D) Saturated/unsaturated fatty-acyl mole ratio (data from Table S1 and Fig. 5D, E). (E) Short-chain/very-long-chain fatty-acyl mole ratio (data from Table S1 and Fig. 5 F, H).

\section{Supplementary Files}

This is a list of supplementary files associated with this preprint. Click to download.

- MyriocinSupp.Figs..pdf

- MyriocinTableS1.xlsx 